\title{
CONTRIBUIÇÃO DO NÍVEL EDUCACIONAL NO COMPORTAMENTO FINANCEIRO PESSOAL
}

\author{
Rafaela Ferreira Maniçoba ${ }^{1}$
}

\begin{abstract}
Resumo: Apesar do crescente número de estudos voltados para a área de finanças pessoais, poucos exploram mudanças comportamentais advindas da melhoria no nível de formação do indivíduo. O objetivo desta pesquisa foi analisar a relação entre a formação superior e o comportamento financeiro pessoal. Em um levantamento com 126 jovens universitários utilizando o método descritivo, verificou-se mudança significativa no comportamento financeiro pessoal, corroborada pelo teste qui-quadrado. $\mathrm{O}$ resultado indicou que a formação superior pode influenciar o comportamento financeiro pessoal desses jovens, principalmente nas faixas de 17 a 22 anos. A partir desse resultado, propõe-se investigar as causas de tal mudança. Para tanto, sugere-se como estudo futuro uma pesquisa utilizando o quadro teórico das Finanças Comportamentais.
\end{abstract}

Palavras-chave: nível educacional, comportamento, finanças pessoais.

\section{EDUCATIONAL LEVEL OF CONTRIBUTION IN BEHAVIOR FINANCIAL STAFF}

\begin{abstract}
Despite the growing number of studies focused on the area of personal finance, few explore behavioral changes resulting from the improvement in the individual's level of education. The objective of this research was to analyze the relationship between higher education formation and personal financial behavior. In a survey of 126 university students using the descriptive method, there was found a significant change in personal financial behavior, corroborated by the chi-square test. The result indicated that higher education formation can influence the personal financial behavior of these young people, especially in the age range of 17 to 22 years. From this result, it is proposed to investigate the causes of such a change. To do so, it is suggested as a future study a research using the theoretical framework of Behavioral Finance.
\end{abstract}

Keywords: educational level, behavior, personal finance.

\section{Introdução}

A gestão dos recursos financeiros no âmbito individual e familiar tem se tornado um tema relevante nos últimos anos. Estudos recentes apontam que a necessidade do planejamento financeiro pessoal ganhará maior importância principalmente devido à iminente crise no sistema de previdência social, que tenderá a afetar a renda de significante parcela da população (MACIEL NETO; GONÇALVES, 2015). A falta de orientação financeira acrescida do consumo excessivo acarreta um grave problema econômico e social, a inadimplência, situação que tende a crescer devido ao cenário atual de crise e desemprego (GUINDANE; MARTINS; CRUZ, 2008).

Durante muito tempo admitiu-se que a alta renda tinha por origem a acumulação de propriedades, mas recentemente verificou-se que, uma grande concentração das altas rendas tem relação direta com a remuneração do trabalho, os neoclássicos explicam esse fato com a teoria do capital humano, quem investe mais em educação obtém salários mais elevados (SINGER, 2008).

Nas recentes pesquisas acadêmicas publicadas da área de finanças, a grande maioria concentra-se nas finanças organizacionais, tornando carente o campo das finanças pessoais, os pesquisadores que já expressaram interesse por esse assunto foram: Matsumoto et al. (2013) que

\footnotetext{
${ }^{1}$ Administradora de empresas e Mestranda em Administração pela FEA-USP. rafaela.manicoba@usp.br
} 
escreveram um artigo com o propósito de analisar a atitude e comportamento dos alunos dos cursos de graduação em administração, ciências contábeis e economia da Universidade do Centro Oeste, Leal e Nascimento (2013) onde propuseram através da administração financeira empresarial ferramentas para o gerenciamento das finanças pessoais e Wohlemberg et al. (2011) que realizaram uma pesquisa para analisar os métodos de gestão utilizados pelos acadêmicos dos cursos do Centro de Ciências Sociais Aplicadas da UNIOESTE.

Não foram encontradas, em bases de dados nacionais, pesquisas analisando se o nível de formação do indivíduo melhora o seu desempenho financeiro pessoal. Com isso, o objetivo desta pesquisa foi estudar a relação entre a formação superior e o comportamento financeiro pessoal. Para a análise deste estudo, adotou-se a pesquisa exploratória-descritiva com um questionário eletrônico direcionado a jovens universitários e para análise dos dados estatística descritiva e análise não-paramétrica.

Para cumprir o objetivo utilizou-se o quadro teórico composto por Pavini (2015), Serasa (2015), D’Urso (2015), IBGE (2015), FIES (2014) e Silveira (2015) descrevendo o cenário econômico e social atual. Bodie e Merton (1997), Gitman (2004), Camargo (2007), Cerbasi (2009) e Kiyosaki e Lechter (2000) fundamentando a gestão financeira pessoal. Doron (2001), Chiavenato (2014), Hersey e Blanchard (1977), Chiavenato (2014), Thaler e Sustein (2009) e Michener, Delamater e Myers (2005) relatando sobre o comportamento e fatores de mudanças. Paro (2012) e Frauches (2014) expondo sobre a educação superior como fator de transformação pessoal. Para a fundamentação metodológica utilizou-se Collado, Lucio e Sampieri (2006) e Gil (2002).

\section{Fundamentação Teórica}

\section{Cenário Econômico e Social Atual}

O modelo de gestão adotado no Brasil é o democrático, e isso afeta o planejamento financeiro empresarial e familiar, pois com a troca de gestores e partidos a cada quatro ou oito anos podem ocorrer significantes mudanças no cenário econômico e social. Um período marcante foi vivenciado até meados de 1990 onde os brasileiros passaram por fortes desequilíbrios financeiros, os preços alteravam a todo instante, consequências da descontrolada inflação do período. Com a implantação do plano Real em 1994, houve a estabilização da moeda facilitando os planejamentos financeiros e aumentando o poder de consumo (PAVINI, 2015).

Com o passar dos anos esse poder de consumo foi acelerado devido as novas fontes de pagamentos e a redução de comprovação de renda, aumentando o índice de inadimplência. Como consequência temos hoje uma parcela equivalente à $24,5 \%$ da população brasileira inadimplente 
(SERASA, 2015). E segundo D’Urso (2015), nos jovens entre 18 e 24 anos essa parcela é ainda mais intensa alcançando aproximadamente 6,3 milhões o equivalente à $26 \%$ dessa população.

Essa faixa etária é normalmente o período de inserção em um curso superior e ingresso no mercado de trabalho, porém muitas vezes esses jovens não possuem estabilidade financeira adequada para investir em educação, por isso buscam alternativas de ajuda de custo total ou parcial, como bolsas, financiamentos, entre outros.

Segundo pesquisas realizadas em 2008 pelo IBGE (2015), o estado de São Paulo detinha na faixa etária de nossa pesquisa 18 à 29 anos aproximadamente 8.369 milhões de indivíduos, $12,7 \%$ destes jovens frequentam cursos superiores públicos e $87,3 \%$ particular. Uma pesquisa realizada em 2013 com essa população ilustrou os seus recursos financeiros.

Gráfico 1. Renda aproximada dos jovens na faixa etária 18 - 29 anos em 2013.

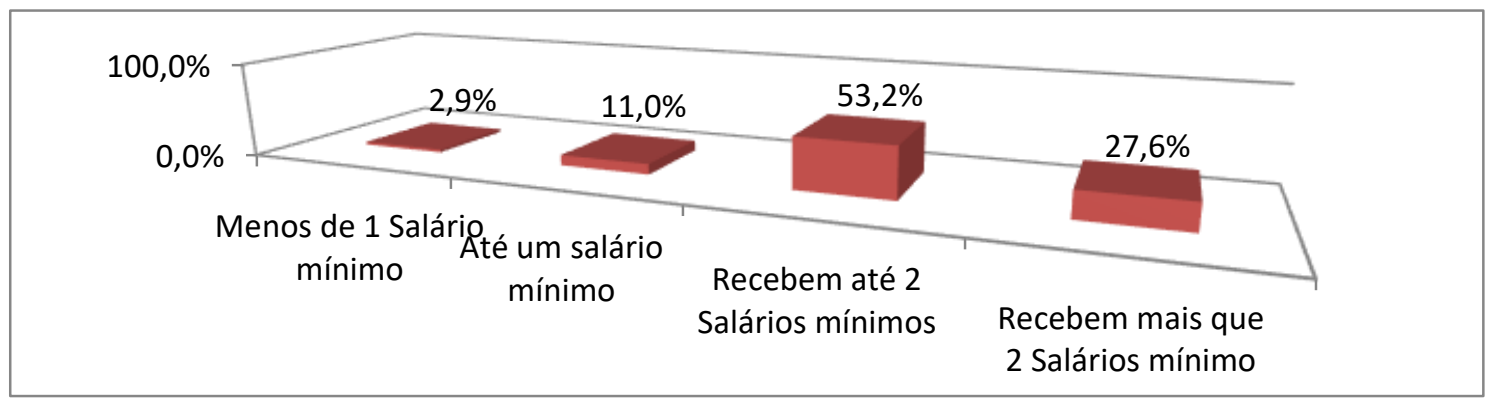

Fonte: Adaptado IBGE (2015).

Com base no gráfico 1 é possível extrair que a maioria dessa população jovem não possui renda suficiente para sobrevivência e educação, sendo que no Brasil há uma inversão de valores, estudantes de baixa renda que sempre estudaram em escolas públicas muitas vezes não conseguem ingressar em universidades públicas apenas com conhecimentos advindos desse sistema, caso almejem tal vaga preparam-se em cursos pré-vestibulares as vezes até por anos. Então uma alternativa criada pelo governo foram as bolsas e financiamentos para cursos superiores particulares.

Porém, no ano de 2015, devido aos excessos nos gastos governamentais, foram necessárias algumas mudanças em projetos sociais, como o FIES (Fundo de Financiamento Estudantil), que é um programa do Ministério da Educação (MEC) destinado à concessão de financiamento a estudantes regularmente matriculados em cursos superiores não gratuitos e com avaliação positiva nos processos conduzidos pelo Ministério da Educação (FIES, 2014), para equilibrar o orçamento se fez necessário à redução de bolsas desse programa, contribuindo para o egresso de muitos jovens em cursos superiores e provavelmente ocasionará o crescimento da 
inadimplência, pois mesmo com essa alternativa alguns jovens ingressam no cadastro de inadimplentes e isso porque nem sempre sabem administrar suas finanças pessoais.

De acordo com (SERASA, 2015) 23,9\% da população de São Paulo são inadimplentes (possuem divididas de mais de $\mathrm{R} \$ 200,00$ por mais de 90 dias) dividindo esses inadimplentes por faixa etária os que lideram o ranking são pessoas com idades entre 18 e 40 anos.

A população brasileira está vivenciando uma forte crise econômica e financeira, que está ocasionando crescimento do desemprego, aumento da pobreza e consequentemente a desigualdade social. O cenário seguinte será imprevisível (SILVEIRA, 2015). Tendo em vista essa turbulência se faz necessário uso e entendimento adequado pelas famílias da gestão financeiro pessoal.

\section{Gestão Financeira Pessoal}

A teoria financeira consiste em um conjunto de concepções que ajudam a organizar o pensamento sobre como alocar recursos escassos ao longo do tempo e um conjunto de modelos quantitativos para ajudar a realizar avaliações de alternativas, tomar decisões e implementá-las (BODIE; MERTON, 1997). Organizações e pessoas possuem preocupações relevantes sobre finanças, pois ambas fazem uso de recursos financeiros, e podem se beneficiar da compreensão desse campo (GITMAN, 2004).

A gestão financeira pessoal consiste em seguir uma estratégia dirigida para a manutenção ou acumulação de bens e valores que irão formar o patrimônio de uma pessoa e de sua família. Uma opção é dividir o planejamento financeiro pessoal em uma linha temporal como de curto, médio e longo prazo, assim pode auxiliar nas compras de bens duráveis e de commodities, sem alterar a rotina atual da família, garantindo a estabilidade moral e psicológica do indivíduo (CAMARGO, 2007).

A organização das finanças pessoais está diretamente ligada a características individuais de organização, persistência e dedicação individual, porém o monitoramento e controle das dívidas inevitavelmente são realizados por caderno de anotações ou planilhas eletrônicas, algo meio difícil levando em consideração a rotina atual e a dificuldade de alguns indivíduos com determinados conceitos matemáticos, advindos dos bancos escolares, local onde ainda não possui educação financeira pessoal (CERBASI, 2009).

Kiyosaki e Lechter (2000) enfatizam que fundamentos financeiros deveriam ser ensinados desde os primeiros anos escolares, uma vez que esse será um assunto que acompanhará qualquer indivíduo ao logo da sua vida, isso é um fator preponderante para quem pretende adquirir equilíbrio financeiro pessoal. 
A compreensão da gestão financeira pessoal permite que o indivíduo atue ativamente na administração de seus bens e na aquisição de novas fontes de subsistência para aposentaria, algo relevante tendo em vista o cenário atual turbulento e incerto da Previdência Social. Mais o que determina o sucesso ou fracasso na administração financeira pessoal é o comportamento individual e social, pois existem pessoas que conseguem comprar apenas o necessário e outras que são persuadidas pelos grupos de convívios sociais a comprarem por modismo.

\section{Comportamento e Fatores de mudanças}

O termo comportamento teve sua origem em 1908 com Henri Piéron na França e 1913 com John B. Watson nos Estados Unidos, o definiram como o conjunto de procedimentos ou reações do indivíduo ao ambiente que o cerca em determinadas circunstâncias, o meio. A corrente da psicologia que se ocupou diretamente com o comportamento como um processo fisiológico foi o Behaviorismo (DORON, 2001).

O Behaviorismo surgiu por volta de 1940 na administração, como uma oposição a Teoria Clássica rígida e mecanicista da época, redefiniu todos os conceitos administrativos e propôs novas proposições sobre a motivação humana, essa teoria explica o comportamento organizacional fundamentando-se no comportamento individual das pessoas (CHIAVENATO, 2014).

O comportamento individual é orientado principalmente pelo desejo de atingir algum objetivo, esse objetivo nem sempre é conscientemente conhecido pelo indivíduo e por isso dificilmente são suscetíveis de exame e avaliação. As pessoas nem sempre estão cientes de tudo aquilo que desejam e, por isso, grande parte de seu comportamento são influenciados por necessidades e motivos inconscientes (HERSEY; BLANCHARD, 1977).

Abraham Maslow apresentou uma teoria baseada na motivação humana com cinco necessidades organizadas em níveis hierárquicos de importância e influência: (1) Necessidades fisiológicas; (2) Necessidades de segurança; (3) Necessidades sociais; (4) Necessidades de estima e; (5) Necessidades de autorrealização. Essa teoria afirma que somente quando um nível inferior de necessidades está satisfeito é que o nível imediatamente mais elevado surge no comportamento da pessoa. Nem todas as pessoas conseguem chegar ao topo da pirâmide de necessidades e mais de uma necessidade pode ser saciada ao mesmo tempo (CHIAVENATO, 2014).

O comportamento pode mudar se aumentar a força de um motivo existente, até o ponto em que se torna o motivo mais intenso. A força de alguns motivos pode aparecer com um padrão cíclico, como a necessidade de alimento, repete-se independente da maior ou menor satisfação 
em determinado movimento. É possível aumentar ou retardar a velocidade desse padrão cíclico através da modificação do ambiente, porém é a percepção, ou interpretação da realidade, que influi no comportamento real da pessoa (HERSEY; BLANCHARD, 1977).

De acordo com Thaler e Sunstein (2009), existe um comportamento na linguagem econômica, denominado "dinamicamente inconsistente". Inicialmente, as pessoas preferem A à B, porém mais tarde, escolhem B no lugar de A. É possível notar inconsistência dinâmica em várias situações, porém a maioria das pessoas percebe que a tentação existe, e toma providências para superá-la. O nosso comportamento reflete certa ingenuidade sobre os efeitos que o contexto pode causar na escolha.

Para Michener, Delamater e Myers (2005) a mudança de comportamento pode ocorrer quando uma pessoa muda o papel que ela ocupa, pois, essa mudança de papel acarreta expectativas e demandas diferentes. A mudança no comportamento também resulta de mudanças no tipo, na intensidade e na frequência do reforço recebido ou de mudanças nas crenças e atitudes. A mudança comportamental pode ainda ocorrer por mudanças nos padrões defendidos pelos outros e aceitos como relevantes.

Durante o desenvolvimento pessoal e profissional pode-se alterar a forma de pensar e se comportar, isso porque com os conhecimentos advindos do ambiente externo mudam a percepção sobre um determinado assunto sendo a educação um fator de transformação pessoal.

\section{Educação Superior como fator de transformação pessoal}

A educação se revela como fator de transformação social, também, em seu caráter intrínseco de apropriação do saber historicamente acumulado, visto que, por meio dela, a classe revolucionária se apodera da ciência, da tecnologia, da filosofia, da arte, enfim, de todas as conquistas culturais realizadas pela humanidade em seu desenvolvimento histórico e que hoje se concentram nas mãos da minoria dominante e são transmitidas às novas gerações por meio de algum processo educativo (PARO, 2012).

O processo educativo é complexo, sendo quase impossível a transmissão total do saber acumulado por pais ou membros mais velhos. Por isso, na sociedade moderna, esse produto do desenvolvimento histórico juntamente com a velocidade e o dinamismo da renovação desse saber são passados por instituições formalmente destacadas para essa tarefa, onde atuam de forma sistemática e organizada (PARO, 2012).

Segundo Frauches (2014), as instituições privadas de educação superior têm contribuído, significativamente, para a redução das desigualdades regionais e sociais, em contrapartida às instituições públicas, particularmente as mantidas pela União, localizadas prioritariamente, nas 
capitais, atendem à elite. Devido à omissão do Estado a iniciativa privada atende as demandas sociais dos grandes centros metropolitanos e de pequenas cidades, abrindo possibilidades para que trabalhadores cursem o ensino superior no período noturno. Atualmente as instituições privadas representam $90 \%$ do total das instituições em funcionamento no País, sendo responsável pela formação de mais de $70 \%$ dos profissionais de nível superior em atuação no mercado.

\section{Metodologia}

Essa pesquisa é de natureza básica pois, conforme Collado, Lucio e Sampieri (2006), essa modalidade visa produzir conhecimentos e teorias. O enfoque utilizado é quantitativo, pois segundo esse autor é o método que utiliza a coleta e análise de dados para responder às questões de pesquisa e testar as hipóteses estabelecidas previamente, confiando na medição numérica, na contagem e frequentemente no uso de estatística para estabelecer com exatidão os padrões de comportamento de uma população.

Quanto aos objetivos essa pesquisa é descritiva, pois visa descrever as características de determinada população ou estabelecimento de relações entre variáveis, envolvendo o uso de técnicas padronizadas de coleta de dados, permitindo visualizar uma situação e categorizar as observações (COLLADO; LUCIO; SAMPIERI, 2006).

Para os procedimentos técnicos utilizou-se a forma bibliográfica, de campo e levantamento de dados (GIL, 2002). O propósito desta pesquisa foi analisar a relação entre formação superior e o desempenho financeiro pessoal. Para tanto, utilizou-se um questionário on-line que pesquisou as características de 126 universitários de uma faculdade localizada na cidade de Praia Grande, litoral sul de São Paulo. Os dados foram analisados com estatística nãoparamétrica utilizando o teste Qui-Quadrado com o software Minitab 15.

A Pesquisa foi realizada eletronicamente por conveniência com alunos que ingressaram no $1^{\circ}$ semestre de 2015 nos cursos de administração e ciências contábeis. Essa faculdade possuía no período da análise aproximadamente 234 alunos matriculados nesses cursos.

A definição da amostra foi elaborada através da equação 1 sugerida por Arnal et al. (1991), para populações inferiores a 100.000 e com $n$ conhecido.

Equação 1. $\mathrm{n}=\frac{\mathrm{z}_{\mathrm{a} / 2^{2}} \mathrm{p} \cdot \mathrm{q} \cdot \mathrm{N}}{\mathrm{e}^{2}(\mathrm{~N}-1)+\mathrm{z}_{\mathrm{a} / \mathrm{z}^{2} \cdot \mathrm{p} \cdot \mathrm{q}}}$

Onde: "N = número de elementos da amostra"; "p = probabilidade de sucesso"; "q = probabilidade de fracasso"; "e = probabilidade de erro"; " $\mathrm{Z}_{\mathrm{a} / 2}=$ variável padronizada na distribuição normal conforme tabela 1 ”. 
Tabela 1. Valores de $Z_{a / 2}$ correspondentes aos graus de confiança mais utilizados.

\begin{tabular}{c|c|c|c}
\hline Grau de Confiança & $\mathbf{a}$ & $\mathbf{a} / \mathbf{2}$ & $\mathbf{Z}_{\mathrm{a} / \mathbf{2}}$ \\
\hline $\mathbf{9 0 \%}$ & 0,10 & 0,05 & 1,645 \\
\hline $\mathbf{9 5 \%}$ & 0,05 & 0,025 & 1,960 \\
\hline $\mathbf{9 9 \%}$ & 0,01 & 0,005 & 2,576 \\
\hline
\end{tabular}

Fonte: Anderson et al. (2013).

O nível de confiança utilizado foi de $90 \%$ e o erro amostral de 5\%, aplicando a equação 1 resultou o valor de 125,73. Assim é possível afirmar que essa pesquisa retratou toda a população dessa faculdade.

O instrumento de pesquisa foi estruturado a partir da revisão da literatura em função de itens que permitiram auferir o comportamento financeiro pessoal. As questões do instrumento sobre o comportamento financeiro foram elaboradas de forma a identificar comportamentos sobre a gestão de finanças pessoais. Foi feito um pré-teste com 5 estudantes, que não participaram da base final. A pesquisa foi realizada no segundo semestre de 2015. Com isso, garantiu-se que os participantes ainda não haviam tido disciplinas relacionadas às finanças pessoais.

\section{Análise e Interpretação dos Dados}

A primeira parte do questionário traçou o perfil pessoal e social referente às finanças pessoais dos estudantes, essas informações foram distribuídas nas tabelas 2, 3, 4, 5, 6, 7, 8 e 9.

A tabela 2 define a faixa etária predominante dos entrevistados, esperava-se que fosse entre 17 e 24 anos, pois habitualmente é a idade de ingresso em cursos superiores, mas a faixa predominante foi de 26 a 28 anos.

Tabela 2. Faixa etária dos entrevistados

\begin{tabular}{l|c|c}
\hline \multicolumn{1}{c|}{ Idade } & Freq. & \% \\
\hline $\mathbf{1 7}$ a 19 anos & 24 & $19 \%$ \\
\hline $\mathbf{2 0}$ a 22 anos & 26 & $21 \%$ \\
\hline $\mathbf{2 3}$ a 25 anos & 21 & $17 \%$ \\
\hline $\mathbf{2 6}$ a 28 anos & 28 & $22 \%$ \\
\hline Mais de 29 anos & 27 & $21 \%$ \\
\hline Total & $\mathbf{1 2 6}$ & $\mathbf{1 0 0 \%}$ \\
\hline
\end{tabular}

Fonte: Dados da Pesquisa.

A tabela 3 ilustra que $76 \%$ dos respondentes são do sexo feminino, afirmando a posição atual da mulher no mercado de trabalho. 
Tabela 3. Divisão por sexo dos entrevistados

\begin{tabular}{l|c|c}
\hline \multicolumn{1}{c|}{ Sexo } & Freq. & \% \\
\hline Feminino & 96 & $76 \%$ \\
\hline Masculino & 30 & $24 \%$ \\
\hline Total & 126 & $100 \%$ \\
\hline
\end{tabular}

Fonte: Dados da Pesquisa.

A tabela 4 corrobora os dados do IBGE (2015) onde define que a renda média predominante na cidade de Praia Grande é de 1 a 3 salários mínimos por família, porém tendo em vista o custo de vida no ano de 2015, esse valor para manter uma família e custear educação é considerado muito baixo.

\section{Tabela 4. Renda Familiar dos entrevistados}

\begin{tabular}{l|c|c|c|c|c|c}
\hline \multicolumn{1}{c}{ Renda Familiar } & \multicolumn{2}{c|}{ Administração } & \multicolumn{2}{c|}{ Ciências Contábeis } & \multicolumn{2}{c}{ Total } \\
\cline { 2 - 7 } & Freq. & $\%$ & Freq. & \% & Freq. & $\%$ \\
\hline Menos de 1 salário mínimo & 0 & $0 \%$ & 0 & $0 \%$ & 0 & $0 \%$ \\
\hline De 1 a 3 salários mínimos & 42 & $63 \%$ & 44 & $75 \%$ & 86 & $68 \%$ \\
\hline De 4 a 6 salários mínimo & 21 & $31 \%$ & 12 & $20 \%$ & 33 & $26 \%$ \\
\hline De 7 a 9 salários mínimos & 0 & $0 \%$ & 3 & $5 \%$ & 3 & $2 \%$ \\
\hline Acima de 10 salários mínimos & 4 & $6 \%$ & 0 & $0 \%$ & 4 & $3 \%$ \\
\hline Total & 67 & $100 \%$ & 59 & $100 \%$ & 126 & $100 \%$ \\
\hline
\end{tabular}

Fonte: Dados da Pesquisa.

A tabela 5 relata a renda pessoal, a qual também predomina a faixa de 1 a 3 salários mínimos, porém a faixa "menos de um salário mínimo" também possui um índice alto, fato que corrobora para o grande número de bolsas nessa faculdade distribuídas na tabela 6 .

Tabela 5. Renda Pessoal dos entrevistados

\begin{tabular}{c|c|c|c|c|c|c}
\hline \multicolumn{2}{c}{ Renda Pessoal } & \multicolumn{2}{|c|}{ Administração } & \multicolumn{2}{c|}{ Ciências Contábeis } & \multicolumn{2}{c}{ Total } \\
\cline { 2 - 7 } & Freq. & $\mathbf{\%}$ & Freq. & $\%$ & Freq. & $\%$ \\
\hline Menos de 1 salário mínimo & 21 & $31 \%$ & 13 & $22 \%$ & 34 & $27 \%$ \\
\hline De 1 a 3 salários mínimos & 43 & $64 \%$ & 43 & $73 \%$ & 86 & $68 \%$ \\
\hline De 4 a 6 salários mínimos & 3 & $4 \%$ & 3 & $5 \%$ & 6 & $5 \%$ \\
\hline De 7 a 9 salários mínimos & 0 & $0 \%$ & 0 & $0 \%$ & 0 & $0 \%$ \\
\hline \multicolumn{1}{c|}{ Total } & $\mathbf{6 7}$ & $\mathbf{1 0 0 \%}$ & $\mathbf{5 9}$ & $\mathbf{1 0 0 \%}$ & $\mathbf{1 2 6}$ & $\mathbf{1 0 0 \%}$ \\
\hline
\end{tabular}

Fonte: Dados da Pesquisa.

Tabela 6. Taxa de bolsistas entre os entrevistados

\begin{tabular}{l|r|r|r|r|r|r}
\hline \multirow{2}{*}{ Bolsista } & \multicolumn{2}{|c|}{ Administração } & \multicolumn{2}{c|}{ Ciências Contábeis } & \multicolumn{2}{c}{ Total } \\
\cline { 2 - 7 } & \multicolumn{1}{c|}{ Freq. } & \multicolumn{1}{c|}{$\%$} & \multicolumn{2}{c}{ Freq. } & \multicolumn{1}{c}{ Freq. } & \multicolumn{1}{c}{$\%$} \\
\hline Sim & 58 & $87 \%$ & 54 & $92 \%$ & 112 & $89 \%$ \\
\hline Não & 9 & $13 \%$ & 5 & $8 \%$ & 14 & $11 \%$ \\
\hline Total & 67 & $100 \%$ & 59 & $100 \%$ & 126 & $100 \%$ \\
\hline
\end{tabular}

Fonte: Dados da Pesquisa. 
A tabela 7 exibe as percepções individuais perante a administração e controle dos recursos financeiros pessoais. No geral todos os entrevistados consideram muito importante $(80 \%)$ e importante $(20 \%)$, porém a tabela 8 , que relata o comportamento financeiro pessoal desses jovens após o pagamento de suas contas mensais, 57,1\% não conseguem poupar nenhuma quantia, situação que pode atrapalhar seus futuros projetos.

Tabela 7. Percepção individual sobre finanças pessoais e controle financeiro

\begin{tabular}{l|c|c|c|c|c|c}
\hline & \multicolumn{2}{|c|}{ Administração } & \multicolumn{2}{c|}{ Ciências Contábeis } & \multicolumn{2}{c}{ Total } \\
\cline { 2 - 7 } & Freq. & \% & Freq. & \% & Freq. & \% \\
\hline Muito Importante & 53 & $79 \%$ & 48 & $81 \%$ & 101 & $80 \%$ \\
\hline Importante & 14 & $21 \%$ & 11 & $19 \%$ & 25 & $20 \%$ \\
\hline Pouco Importante & 0 & $0 \%$ & 0 & $0 \%$ & 0 & $0 \%$ \\
\hline Total & 67 & $100 \%$ & 59 & $100 \%$ & 126 & $100 \%$ \\
\hline
\end{tabular}

Fonte: Dados da Pesquisa.

Tabela 8. Comportamento individual após o pagamento das dívidas mensais

\begin{tabular}{l|c|c|c|c|c|c}
\hline \multirow{2}{*}{$\begin{array}{l}\text { Guarda alguma quantia em } \\
\text { poupança ou outro investimento? }\end{array}$} & \multicolumn{2}{|c|}{ Administração } & \multicolumn{2}{c|}{ Ciências Contábeis } & \multicolumn{2}{c}{ Total } \\
\cline { 2 - 7 } & Freq. & $\mathbf{\%}$ & Freq. & \% & Freq. & $\%$ \\
\hline Não & 40 & $60 \%$ & 32 & $54 \%$ & 72 & $57 \%$ \\
\hline Sim. De R\$50,00 a R\$100,00 & 16 & $24 \%$ & 15 & $25 \%$ & 31 & $25 \%$ \\
\hline Sim. De R\$101,00 a R\$300,00 & 7 & $10 \%$ & 8 & $14 \%$ & 15 & $12 \%$ \\
\hline Sim. De R\$ 301,00 a R\$500,00 & 3 & $4 \%$ & 1 & $2 \%$ & 4 & $3 \%$ \\
\hline Sim. Mais de R\$500,00 & 1 & $1 \%$ & 3 & $5 \%$ & 4 & $3 \%$ \\
\hline
\end{tabular}

Fonte: Dados da Pesquisa.

A tabela 9 descreve como esses jovens administram seus recursos. Dos respondentes $51 \%$ conseguem sanar suas dívidas, mas passam o mês sem dinheiro, 37\% sanam suas dívidas e ainda investem parte do salário, 5\% não conseguem sanar suas dívidas mais a família ajuda e $8 \%$ acabam se endividando.

Tabela 9. Administração dos recursos pessoais mensais

\begin{tabular}{l|c|c|c|c|c|c}
\hline \multirow{2}{*}{$\begin{array}{l}\text { Quando recebe consegue pagar todas } \\
\text { as suas dividas? }\end{array}$} & \multicolumn{2}{|c|}{ Administração } & \multicolumn{2}{c|}{ Ciências Contábeis } & \multicolumn{2}{c}{ Total } \\
\cline { 2 - 7 } Sim, mas fico sem dinheiro. & Freq. & $\%$ & Freq. & $\%$ & Freq. & $\%$ \\
\hline $\begin{array}{l}\text { Sim e ainda invisto parte do meu } \\
\text { salário }\end{array}$ & 20 & $35 \%$ & 26 & $43 \%$ & 46 & $37 \%$ \\
\hline $\begin{array}{l}\text { Não, mas minha família me ajuda } \\
\text { financeiramente. }\end{array}$ & 3 & $5 \%$ & 3 & $5 \%$ & 6 & $5 \%$ \\
\hline Não e acabo me endividando & 7 & $11 \%$ & 3 & $5 \%$ & 10 & $8 \%$ \\
\hline
\end{tabular}

Fonte: Dados da Pesquisa.

As tabelas 10 e 11 relatam o foco dessa pesquisa, que se restringiu ao ensino superior e aos jovens com mais de 17 anos. Para identificar se houve mudança significativa na amostra foi 
utilizada uma ferramenta estatística de hipóteses, teste Qui-Quadrado de Pearson, que serve para verificar se a diferença observada na amostra é significante e o resultado foi baseado na equação 2 proposta por Siegel e Castellan Junior (2006, p. 65).

Equação 2. $\quad X^{2}=\sum_{i=k}^{k}=\frac{\left(O_{i}-E_{i}\right)^{2}}{E_{i}}$

Onde: " $\mathrm{O}_{\mathrm{i}}=$ número de casos observados na i-ésima categoria", " $\mathrm{E}_{\mathrm{i}}=$ número de casos esperado na i-ésima categoria quando $\mathrm{H}_{0}$ é verdadeira" e " $\mathrm{K}$ = número de categorias".

Tabela 10. Teste Qui-Quadrado para significância da mudança observada na Pesquisa antes e após o ingresso em curso superior

\begin{tabular}{|l|c|c|c|c|c|}
\hline & \multicolumn{3}{|c|}{ Observado } & \multirow{2}{*}{ Esperado } & $\begin{array}{c}\text { Qui- } \\
\text { Quadrado }\end{array}$ \\
\cline { 2 - 6 } & Antes & Depois & Total & & \\
\hline $\begin{array}{l}\text { 1. Comprava tudo o que gostava, mesmo } \\
\text { comprometendo meu salário. }\end{array}$ & 30 & 6 & 36 & 18 & 8,000 \\
\hline $\begin{array}{l}\text { 2. Comprava apenas o que precisava, mas } \\
\text { usava o cartão de crédito. }\end{array}$ & 44 & 37 & 81 & 40,5 & 0,302 \\
\hline $\begin{array}{l}\text { 3. Comprava tudo o que precisava, sem } \\
\text { comprometer meu próximo salário. }\end{array}$ & 43 & 43 & 86 & 43 & 0,000 \\
\hline $\begin{array}{l}\text { 4. Evitava Compras. } \\
\text { Total }\end{array}$ & 9 & 40 & 49 & 24,5 & 9,806 \\
\hline
\end{tabular}

Fonte: A autora.

Conforme a tabela 10 o valor obtido do qui-quadrado foi de 18,109 e ao testar $\mathrm{H}_{0}$ ao nível 0,05, o valor crítico é de 5,99, ou seja, o teste comprovou que existe mudança significativa de comportamento em relação às finanças pessoais de jovens ao ingressarem em curso superior mesmo sendo bolsista integral. As questões que realmente corroboraram para essa afirmativa foram: (1) Comprava tudo o que gostava, mesmo comprometendo meu salário e; (4) Evitava Compras. Para aprofundar um pouco mais essa pesquisa a tabela 11 relata se a idade é um fator significante que compromete essa mudança. 
Tabela 11. Teste Qui-quadrado para identificar se a idade é fator relevante na mudança de comportamento financeiro pessoal

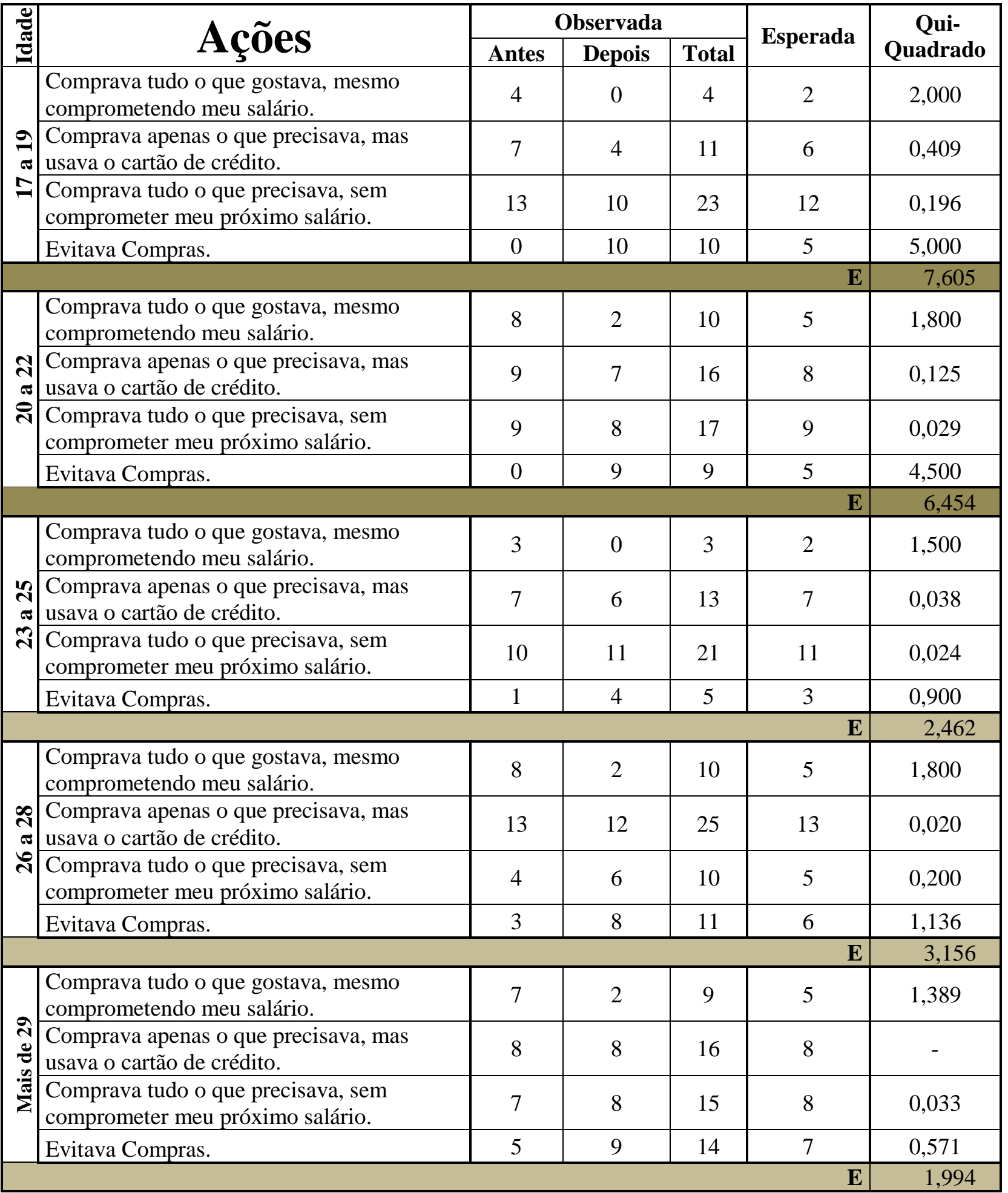

Fonte: A autora.

Ao testar $\mathrm{H}_{0}$ ao nível 0,05, o valor crítico de qui-quadrado é de 5,99, e como resultado obteve-se que as idades que manifestaram significante mudança no comportamento financeiro 
pessoal ao ingressar no curso superior foram as faixas de 17 a 19 anos e 20 a 22 anos, as demais não tiveram mudanças significativas.

\section{Considerações Finais}

A pesquisa teve por finalidade estudar a relação entre a formação superior e o comportamento financeiro pessoal de jovens universitários investigando se o ingresso na universidade melhorou o seu desempenho financeiro pessoal. Foi possível não rejeitar a relação positiva por meio do teste qui-quadrado sendo que para entender em qual faixa etária essa mudança ocorria com mais significância aplicou-se novamente o teste que resultou nas faixas de 17 a 22 anos.

Foi possível inferir com essa pesquisa que, mesmo cursando a faculdade com programas de bolsas, ou seja, não modificando bruscamente a renda pessoal desses jovens, o cenário acadêmico contribui para a melhora do comportamento no processo de compras e na administração dos recursos pessoais, principalmente nos mais jovens.

Para que fosse ainda mais eficaz essa mudança de comportamento, a educação financeira pessoal deveria ser disciplina padrão em cursos superiores, para que assim os estudantes tivessem conhecimentos e ferramentas específicas para uso contínuo visando administração eficiente de suas riquezas pessoais, possibilitando futuras mudanças no cenário econômico e social brasileiro.

As limitações desta pesquisa concernem à generalização dos resultados, pois a pesquisa realizada analisou parcela de estudantes de dois cursos superiores em uma instituição localizada no litoral do estado de São Paulo. Pesquisas futuras podem permitir melhorar a generalização dos resultados ao replicar o instrumento para outras instituições e estudantes de outros cursos. Outras pesquisas também podem ampliar o escopo teórico de forma a incluir modelos de Finanças Comportamentais.

\section{Referências}

ANDERSON, D. R.; SWEENEY, D. J.; WILLIAMS, T.A. Estatística Aplicada à Administração e Economia. $3^{\mathrm{a}}$ ed. São Paulo: Cengage Learning, 2013.

ARNAL, J.; RINCÓN, D.; LATORRE, A. Investigación educativa: fundamentos y metodologias. Madrid: Labor, 1991.

BODIE, Zvi; MERTON, Robert C. Finance: Preliminary Edition. Rio de Janeiro: PrenticeHall do Brasil, 1997.

CAMARGO, C. Planejamento financeiro pessoal e decisões financeiras organizacionais: relações e implicações sobre o desempenho organizacional no varejo. Curitiba, 2007. Centro de Pesquisa e Pós-Graduação em Administração, Universidade Federal do Paraná, 2007. 
CERBASI, Gustavo. Casais Inteligentes Enriquecem Juntos. São Paulo: Editora Gente, 2004. CHIAVENATO, Idalberto. Introdução à Teoria Geral da Administração. $9^{a}$ ed. Barueri, SP: Manole, 2014.

COLLADO, C.F.; LUCIO, P.B.; SAMPIERI, R.H. Metodologia de Pesquisa. $3^{\text {a }}$ ed. São Paulo: McGraw-Hill, 2006.

D’URSO, Maria Lúcia. Endividamento Atinge População Jovem do Brasil. Disponível em: http://www.ibracon.com.br/ibracon/Portugues/detNoticia.php?cod=2575. Acesso em 20 abr. 2015.

DORON, Roland; PAROT, Françoise (orgs.). Comportamento in Dicionário de Psicologia. $1^{\mathrm{a}}$ edição. São Paulo: Ática, 2001.

FIES. Ministério da Educação. Prestação de Contas Ordinárias anual: Relatório de Gestão do exercício de 2014. Disponível em: http://webcache.googleusercontent.com/search?q=cache:Bncpox7F2oJ:portal.mec.gov.br/index.php\%3Foption\%3Dcom_docman\%26task\%3Ddoc_download \%26gid\%3D17528\%26Itemid\%3D+\&cd=1\&h1=pt-BR\&ct=clnk\&gl=br. Acesso em 16 mai. De 2015.

FIES. Programa de Financiamento Estudantil. Quem acredita em si mesmo merece o nosso crédito, explicação e perguntas frequentes sobre o programa. Disponível em: http://sisfiesportal.mec.gov.br/faq.html. Acesso em 30 mar. 2015.

FRAUCHES, Celso da Costa. Educação superior: cobras \& lagartos. Brasília: Ilape, 2015.

GIL, A. C. Como elaborar projetos de pesquisa. $4^{\text {a }}$ ed. São Paulo: Atlas, 2002.

GITMAN, L. J. Princípios de Administração Financeira. 10 a ed. São Paulo: Pearson Addison Wesley, 2004.

GUINDANI, Roberto Ari; MARTINS, Tomás Sparano; CRUZ, June Alisson Westarb. Finanças Pessoais. Curitiba: Ibpex, 2008.

HERSEY, Paul; BLANCHARD, Kenneth H. Psicologia para Administradores de Empresas. $2^{\mathrm{a}}$ ed. São Paulo: EPU, 1977.

IBGE, Cidades. São Paulo: Praia Grande. Disponível em: http://cidades.ibge.gov.br/xtras/perfil.php?codmun=354100. Acesso em 13 jun. 2015.

KIYOSAKI, Robert T.; LECHTER, Sharon L. Pai Rico, Pai Pobre. $46^{\text {a }}$ ed. Rio de Janeiro. Editora Elsevier, 2000.

LEAL, C. P.; NASCIMENTO, J.A.R. Planejamento Financeiro Pessoal. Artigo Científico. 2013. Disponível em: http://consut.com.br/artigo201109.pdf. Acesso em 26 jun. 2015.

MACIEL NETO, Alcides Antônio; GONÇALVES, Rafael Recidive. Os Segredos para atingir a riqueza. Minas Gerais: Abril, 2015.

MATSUMOTO, Alberto Shigueru, et al. Finanças Pessoais: Um estudo sobre a importância do Planejamento Financeiro Pessoal. Florianópolis, 2013. Disponível em: http://alaxendrodalpiva.blogspot.com.br/2015/03/financas-pessoais-um-estudo-sobre.html.

Acesso em 01 jul. 2015.

MICHENER, H. Andrew; DELAMATER, John D.; MYERS, Daniel J. Psicologia Social. São Paulo: Pioneira Thomson Learning, 2005.

PARO, Vitor Henrique. Administração Escolar: Introdução Crítica. $17^{a}$ ed. São Paulo: Cortez, 2012. 
PAVINI, Angelo. Fim da Hiperinflação mudou a vida dos brasileiros. Disponível em: https://br.financas.yahoo.com/blogs/blog-pavini/plano-real-20-anos-depois-fim-dahiperinfla\%C3\%A7\%C3\%A3o-165653380.html. Acesso em 23 mai. 2015.

SERASA. Mapa da Inadimplência no Brasil. Estudo inédito da Serasa Experian traça o Mapa da Inadimplência no Brasil em 2014. Disponível em: http://www.serasaexperian.com.br/estudo-inadimplencia. Acesso em 05 abr. de 2015.

SILVEIRA, Daniel. 2015 é o ano de transição para o cenário econômico. Disponível em: http://gl.globo.com/economia/noticia/2015/04/2015-e-ano-de-transicao-para-o-cenarioeconomico-diz-levy.html. Acesso em 25 jun. 2015.

SIEGEL, S.; CASTELlan,Jr, N.J. Estatística Não Paramétrica para as Ciências do Comportamento. Artmed-Bookman. São Paulo, 2006.

SINGER, Paul. Aprender Economia. 24a ed. São Paulo: Contexto, 2008.

THALER, Richard H.; SUNSTEIN, Cass R. Nudge: O Empurrão para a Escolha Certa. Rio de Janeiro: Elsevier, 2009.

WOHLEMBERG, T.R.; BRAUM, L.M.S.; ROJO, C.A. Finanças Pessoais: uma Pesquisa com os acadêmicos da UNIOESTE campus de Marechal Cândido Rondon. Disponível em: http://e-revista.unioeste.br/index.php/csaemrevista/search/results. Acesso em 02 jun. 2015. 